\title{
Crescimento Alométrico dos Tecidos Ósseo, Muscular e Adiposo na Carcaça de Cordeiros Santa Inês e Bergamácia
}

\author{
Cristiane Leal dos Santos ${ }^{1}$, Juan Ramon Olalquiaga Pérez², Edson Ramos Siqueira ${ }^{3}$, \\ Joel Augusto Muniz ${ }^{4}$, Sarita Bonagúrio ${ }^{5}$
}

\begin{abstract}
RESUMO - O trabalho foi realizado com objetivo de realizar um estudo alométrico dos tecidos ósseo, muscular e adiposo na meia carcaça esquerda de cordeiros em crescimento. Foram utilizados 36 cordeiros machos inteiros, sendo 24 Santa Inês e 12 Bergamácia. Os animais foram confinados em gaiolas individuais e alimentados ad libitum. $\mathrm{O}$ abate ocorreu quando os animais atingiram os pesos vivos de 15, 25, 35 e $45 \mathrm{~kg}$. Após a carcaça ter sido limpa e resfriada, foram obtidos os cortes comerciais a partir da meia carcaça esquerda. A quantidade dos diferentes tecidos foi obtida a partir da dissecação da perna, do lombo, da costeleta, costela/fralda e paleta. A quantidade total dos tecidos ósseo, muscular e adiposo foi obtida pela adição das quantidades de cada corte comercial. O estudo do desenvolvimento relativo da composição tecidual foi feito por meio do modelo de HUXLEY (1932). Constatou-se crescimento heterogônico negativo $(\mathrm{b}<1)$ para o tecido ósseo, crescimento isogônico $(\mathrm{b}=1)$ para o tecido muscular e heterogônico positivo $(\mathrm{b}>1)$ para a gordura, em relação ao peso da $1 / 2$ carcaça.
\end{abstract}

Palavras-chave: alometria, Bergamácia, crescimento, gordura, músculo, osso, Santa Inês

\section{Allometric Growth of Bone, Muscular and Fat Tissues in Carcass of Santa Ines and Bergamacia Lambs}

\begin{abstract}
The work was conducted with the objective to study the allometric growth of the bone, muscular and fat tissues in the left side of growing lamb carcasses. Thirty-six, twenty-four Santa Ines and twelve Bergamacia lambs were used. The animals were kept in individual pens and fed ad libitum diets. The slaughtering was done when the animals reached the live weight of $15,25,35$ and $45 \mathrm{~kg}$. The amount of the different tissues was obtained through the dissection of the left half of the carcass. The amount of the different tissues was obtained through the dissection of the leg, longissimus muscle, rib, breast and shoulder. The total amount of bone, muscle and fat tissues were obtained by the sum of each amount of commercial cut. The study of the relative tissue composition development was carried out using the model developed by HUXLEY (1932). A negative heterogonic $(b<1)$ growth for the bone tissue, an isogonic $(b=1)$ growth for muscular tissue and positive heterogonic $(b>1)$ for the fat tissue in relation to the half side of the carcass was observed.
\end{abstract}

Key Words: allometric, Bergamacia, bone, fat, growth, muscle, Santa Ines

\section{Introdução}

No animal destinado à produção de carne, a carcaça constitui-se no principal produto comercializável. Na composição básica desta, os tecidos muscular, ósseo e adiposo não se desenvolvem de forma isométrica, posto que cada um terá impulso de crescimento distinto em uma fase da vida do animal. Entre os tecidos que constituem a carcaça, destacam-se os músculos, a gordura e os ossos. A idade e o peso em que ocorrem a aceleração ou desaceleração no desenvolvimento de cada tecido, dependem da raça, do sexo e do nível nutricional, entre outros fatores (FORREST et al., 1979).

O desenvolvimento do animal pode ser descrito pelo coeficiente de alometria, permitindo estabelecer o tipo de carcaça ideal, que seria aquela com máxima quantidade de tecido muscular, mínima de tecido ósseo e adequada deposição de gordura exigida pelo mercado a que será destinada.

A composição da carcaça pode ser expressa em termos de dissecação física dos tecidos, pela análise química dos seus constituintes ou por meio de equações baseadas em algumas mensurações da carcaça, ou seja, indicadores que possam predizer a proporção de carne comercial (FERREIRA, 1997). Os tecidos

\footnotetext{
1 Doutoranda do Curso de Zootecnia da UFLA, Caixa Postal, 37 - CEP: 37200-000 - Lavras, MG. E.mail: crisleal@ufla.br

2 Professor PhD do Departamento de Zootecnia, UFLA, Caixa Postal, 37 - CEP: 37200-000 - Lavras, MG. E.mail: jroperez@ufla.br

3 Professor DSc do Departamento da Faculdade de Medicina Veterinária, UNESP - Botucatu. e.r.siqueira@fca.unesp.br

4 Professor DSc do Departamento de Ciências Exatas, UFLA, Caixa Postal, 37 - CEP: 37200-000 - Lavras, MG. E.mail: joamuniz@ufla.br

${ }^{5}$ Mestranda em Zootecnia da UFLA, Caixa Postal, 37 - CEP: 37200-000 - Lavras, MG. E.mail: sasabona@ufla.br
} 
caracterizam-se, pela dissecação física da carcaça, em muscular, ósseo e adiposo, sendo o tecido muscular o mais importante, por apresentar valor comercial.

Os músculos, inicialmente, e depois o tecido adiposo exercem grande influência na composição da carcaça, enquanto os ossos, em nenhum estádio, têm papel dominante na determinação das quantidades relativas dos três tecidos. O tecido ósseo apresenta maior impulso de crescimento em menor idade, enquanto o tecido adiposo tem crescimento em idade mais avançada e o tecido muscular, em idade intermediária (BERG et al., 1978; MÜLLER e PRIMO, 1986).

O conhecimento das modificações que ocorrem durante o período de crescimento são importantes, uma vez que o valor dado ao animal com aptidão para carne depende das mudanças que se produzem nesse período.

Neste trabalho, objetivou-se realizar o estudo do crescimento alométrico dos tecidos ósseo, muscular e adiposo, em relação à meia carcaça esquerda de cordeiros das raças Santa Inês e Bergamácia, dos $15 \mathrm{~kg}$ aos $45 \mathrm{~kg}$ de peso vivo.

\section{Material e Métodos}

O experimento foi desenvolvido no Setor de Ovinocultura, Departamento de Zootecnia da Universidade Federal de Lavras, Minas Gerais. Utilizaram-se 36 cordeiros machos inteiros com peso inicial de $15 \mathrm{~kg}$, sendo 12 da raça Bergamácia e 24 da raça Santa Inês, que foram mantidos sob regime de confinamento, em gaiolas individuais.

A dieta utilizada (Tabela 1) foi constituída de feno triturado de coastcross (Cynodon dactylon), farelo de soja (Glicine max L.), grão de milho (Zea mays L.), calcário calcítico, suplemento mineral e suplemento vitamínico, calculada com base nas exigências nutricionais estabelecidas pelo ARC (1980), para ganho de peso diário esperado de $300 \mathrm{~g}$.

Os cordeiros foram sorteados para serem sacrificados em diferentes pesos: 15, 25, 35 e $45 \mathrm{~kg}$, com aproximadamente as respectivas idades de 50, 100, 140 e 190 dias. O abate foi feito por meio de um corte na artéria carótida e nas veias jugulares, com coleta e pesagem do sangue. Após sangria e retirada da pele, foi feita um abertura ao longo de toda extensão da linha mediana ventral do abdome e procedeu-se à evisceração. Pesaram-se o trato gastrointestinal, bexiga e vesícula biliar, cheios e vazios, para determinação do peso corporal vazio (PCVZ). Retiraram-se a cabeça, os pés, a cauda e os testículos e obteve-se a carcaça do animal.

As carcaças quente foram levadas à câmara fria à temperatura de $2^{\circ} \mathrm{C}$, por um período de 24 horas, sendo mantidas penduradas pela articulação tarso metatarsiana, em ganchos próprios, com distanciamento de $17 \mathrm{~cm}$. Após esse período, proce-

Tabela 1 - Composição da dieta experimental (\%MS)

Table 1 - Composition of the experimental diet (\%DM)

\begin{tabular}{|c|c|c|c|c|c|c|c|}
\hline $\begin{array}{l}\text { Ingrediente } \\
\text { Ingredient }\end{array}$ & $\begin{array}{l}\text { MS } \\
D M \\
(\%) \\
\end{array}$ & $\begin{array}{c}\mathrm{EM}^{1} \\
M E \\
\text { (kcal/kg) }\end{array}$ & $\begin{array}{l}\mathrm{PB} \\
C P \\
(\%) \\
\end{array}$ & $\begin{array}{c}\text { FDN } \\
N D F \\
(\%)\end{array}$ & $\begin{array}{l}\text { FDA } \\
A D F \\
(\%)\end{array}$ & $\begin{array}{c}\mathrm{Ca} \\
\mathrm{Ca} \\
(\%)\end{array}$ & $\begin{array}{c}\mathrm{P} \\
P \\
(\%)\end{array}$ \\
\hline $\begin{array}{l}\text { Grão de milho } \\
\text { Corn grain }\end{array}$ & 66,23 & 2,087 & 6,49 & 14,19 & 2,64 & 0,022 & 0,196 \\
\hline $\begin{array}{l}\text { Farelo de soja } \\
\text { Soybean meal }\end{array}$ & 12,37 & 0,394 & 6,28 & 2,37 & 1,14 & 0,053 & 0,097 \\
\hline $\begin{array}{l}\text { Feno coastcross } \\
\text { Coastcross hay }\end{array}$ & 20,25 & 0,395 & 2,44 & 15,71 & 6,95 & 0,120 & 0,080 \\
\hline $\begin{array}{l}\text { Calcário calcítico } \\
\text { Limestone }\end{array}$ & 0,85 & - & - & - & - & 0,306 & - \\
\hline $\begin{array}{l}\text { Sal } \\
\text { Salt }\end{array}$ & 0,25 & - & - & - & - & - & - \\
\hline $\begin{array}{l}\text { Supl. mineral }{ }^{2} \\
\text { Mineral supplement }\end{array}$ & 0,01 & - & - & - & - & - & - \\
\hline $\begin{array}{l}\text { Supl. vitamínico }{ }^{2} \\
\text { Vitamin supplement }^{2}\end{array}$ & 0,04 & - & - & - & - & - & - \\
\hline Total & 100,00 & 2,876 & 15,21 & 32,27 & 10,73 & 0,501 & 0,373 \\
\hline
\end{tabular}


Rev. bras. zootec.

deu-se à retirada do pescoço e, em seguida, mediante corte longitudinal na carcaça, obtiveram-se metades aproximadamente simétricas, pesando-se a $1 / 2$ carcaça esquerda, a qual foi dividida em cinco cortes comerciais, perna, lombo, costeleta, costela/fralda e paleta (Figura 1).

Como a carcaça foi dividida em cortes comerciais (perna, lombo, costeleta, costela/fralda e paleta) e cada corte, dissecado separadamente, calculou-se a quantidade de osso, músculo e gordura da meia carcaça esquerda, por meio da soma das quantidades destes tecidos por corte, obtendo-se, dessa forma, a composição física da $1 \frac{1}{2}$ carcaça esquerda.

O estudo do crescimento relativo dos cortes foi realizado mediante o modelo da equação exponencial, $\mathrm{Y}=\mathrm{a} \mathrm{X}^{\mathrm{b}}$, transformada logaritmicamente em um modelo linear, $\ln \mathbf{Y}=\ln \mathbf{a}+\mathbf{b} \ln \mathbf{X}+\ln \boldsymbol{\varepsilon} \mathbf{i}$, (HUXLEY, 1932).

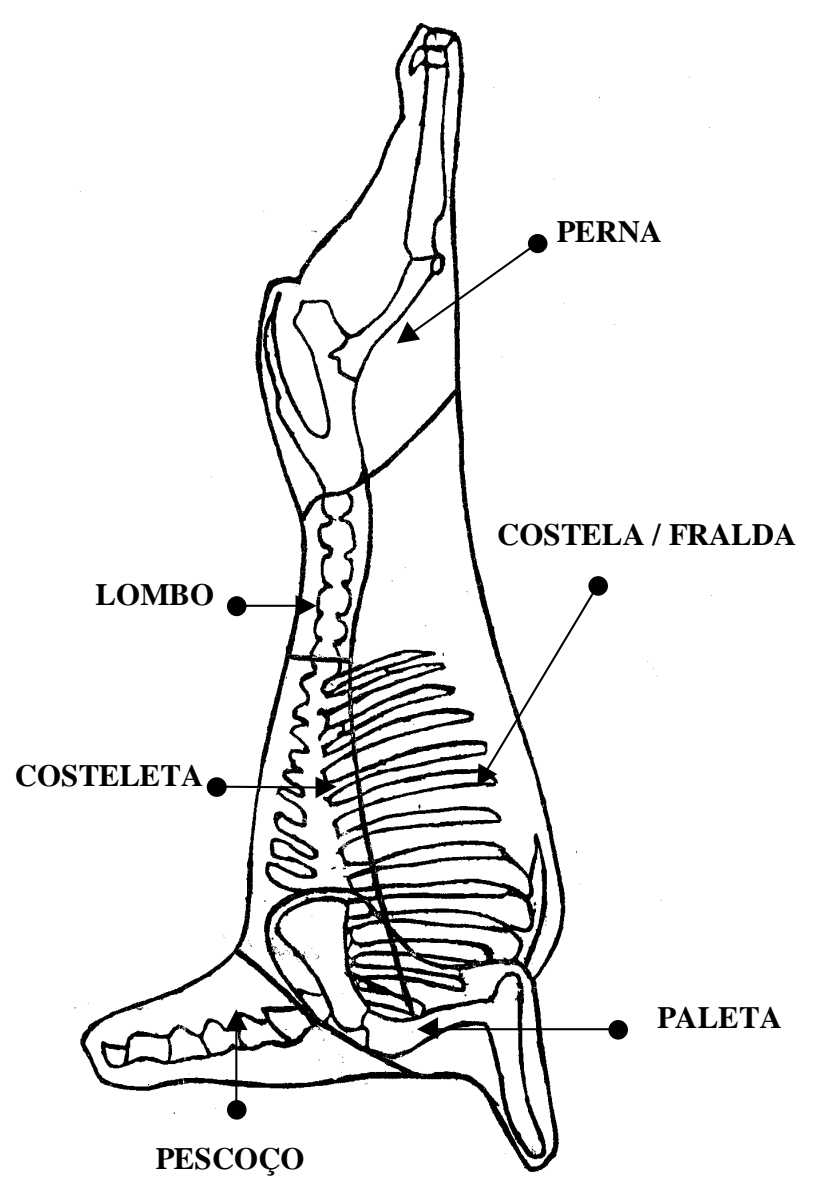

Figura 1- Cortes efetuados na meia carcaça esquerda de cordeiros Santa Inês.

Figure 1 - Cuts determined in 1/2 left carcass of Santa Ines lambs. em que $\mathbf{Y}$ é o peso de cada componente tecidual (osso, músculo e gordura); $\mathrm{X}$, o peso da meia carcaça esquerda fria; a, a intercepção do logaritmo da regressão linear sobre Y e "b"; b, o coeficiente de crescimento relativo ou coeficiente de alometria; $\boldsymbol{\varepsilon}_{\mathbf{i}}$, o erro multiplicativo.

As análises para obtenção dos coeficientes alométricos foram realizadas por intermédio do SAS (1996). Para verificação da hipótese $b=1$, foi realizado o teste "t " (Student) $(\mathrm{a}<0,01$ e $\mathrm{a}<0,05)$. Se $\mathrm{b}=1$, o crescimento foi denominado isogônico, indicando que as taxas de desenvolvimento de " $\mathrm{X}$ " e "Y" foram semelhantes no intervalo de crescimento considerado. Quando $b \neq 1$, o crescimento foi chamado heterogônico, sendo positivo ( $b>1$ ), órgão de desenvolvimento tardio; ou negativo $(b<1)$, órgão de desenvolvimento precoce.

\section{Resultados e Discussão}

O desenvolvimento pode ser medido de diversas formas: medições no corpo ou na carcaça, pesagem de diferentes órgãos, partes ou tecidos. A alometria explica parte das diferenças quantitativas que se produzem entre animais e constitui um meio eficaz para o estudo das carcaças.

Nas Tabelas 2 e 3, são apresentadas as equações de regressão que descrevem o tipo de crescimento que ocorreu com osso, músculo e gordura em relação ao desenvolvimento da carcaça dos cordeiros das raças Santa Inês e Bergamácia, respectivamente.

Tabela 2 - Equações de alometria para osso (O), músculo (M) e gordura (G), em relação ao peso da meia carcaça esquerda (PCE) de cordeiros Santa Inês e verificação da diferença do coeficiente de alometria com a unidade

Table 2 - Equations of allometric for bone (B), muscle (M) and fat $(F)$, in relation to $1 / 2$ left carcass weight (LCW) of Santa Ines lambs and corroboration of the difference of allometry coefficent with the unit

\begin{tabular}{lccc}
\hline $\begin{array}{l}\text { Componentes } \\
\text { teciduais }\end{array}$ & $\begin{array}{c}\text { Equação } \\
\text { Equation } \\
\begin{array}{l}\text { Tissue } \\
\text { components }\end{array}\end{array}$ & $\begin{array}{c}\text { Teste } \mathrm{t} \\
\text { ttest }\end{array}$ & $\mathrm{R}^{2}$ \\
\hline $\begin{array}{l}\text { Osso } \\
\text { Bone }\end{array}$ & $\ln \mathrm{Y}=\ln \mathrm{a}+\mathrm{b} \ln \mathrm{X}$ & $\mathrm{H}=1$ & \\
$\begin{array}{l}\text { Músculo } \\
\text { Muscle }\end{array}$ & $\ln \mathrm{M}=-0,803+0,591 \ln \mathrm{PCE}$ & $* *$ & 91,51 \\
$\begin{array}{l}\text { Gordura } \\
\text { Tat }\end{array}$ & $\ln \mathrm{G}=-2,500+1,413 \ln \mathrm{PCE}$ & $* *$ & 93,85
\end{tabular}

Fat

** Siginificativo a $1 \%$ de probabilidade.

** Significant at $1 \%$ of probability. 
Tabela 3 - Equação de alometria para os componentes teciduais, osso $(O)$, músculo $(M)$ e gordura $(G)$, em relação ao peso da meia carcaça esquerda (PCE) de cordeiros Bergamácia e verificação da diferença do coeficiente de alometria com a unidade

Table 3 - Equation of allometric for tissue components, bone (B), muscle $(M)$ and fat $(F)$, in relation to $1 / 2$ left carcass weight (LCW) of Bergamacia lambs and corroboration of the difference of allometry coefficent with the unit

\begin{tabular}{|c|c|c|c|}
\hline $\begin{array}{l}\text { Componente } \\
\text { teciduais } \\
\text { Tissue } \\
\text { components }\end{array}$ & $\begin{array}{c}\text { Equação } \\
\text { Equation } \\
\ln \mathrm{Y}=\ln \mathrm{a}+\mathrm{b} \ln \mathrm{X}\end{array}$ & $\begin{array}{c}\text { Teste } \mathrm{t} \\
\text { t test } \\
\text { Ho: } \mathrm{b}=1\end{array}$ & $\mathrm{R}^{2}$ \\
\hline $\begin{array}{l}\text { Osso } \\
\text { Bone }\end{array}$ & $\ln \mathrm{O}=-1,013+0,737 \ln \mathrm{PCE}$ & $*$ & 87,7 \\
\hline $\begin{array}{l}\text { Músculo } \\
\text { Muscle }\end{array}$ & $\ln \mathrm{M}=-0,587+0,974 \ln \mathrm{PCE}$ & n.s & 98,1 \\
\hline Gordura & $\ln \mathrm{G}=-3,021+1,680 \ln \mathrm{PCE}$ & $* *$ & 98, \\
\hline
\end{tabular}

* Siginificativo a $5 \%$ de probabilidade.

* Significant at $5 \%$ of probability.

** Significativo a $1 \%$ de probabilidade.

** Significant at $1 \%$ of probability.

Os coeficientes de alometria dos tecidos ósseo e adiposo das carcaça dos cordeiros Santa Inês foram diferentes de $1(b \neq 1)$, implicando que o crescimento do tecido ósseo foi heterogônico negativo $(b<1)$, ou seja, apresentou desenvolvimento precoce em relação ao desenvolvimento da carcaça, e do tecido adiposo, heterogônico positivo ( $b>1$ ), ou seja, desenvolvimento tardio. SILVA (1999) verificou também que o tecido ósseo é o que menos cresce em relação ao peso da carcaça.

O tecido muscular apresentou desenvolvimento semelhante ao da meia carcaça, ou seja, o seu crescimento foi isogônico $(b=1)$. Na Figura 2 são apresentadas as equações de alometria e as respectivas linhas de regressão para os componentes teciduais em relação à carcaça de cordeiros Santa Inês. Observou-se que, em torno dos 7,0 kg de peso da meia carcaça, o tecido ósseo mostrou seu declínio de crescimento e o tecido adiposo aumentou sua deposição na carcaça.

Nos cordeiros Bergamácia, o comportamento dos tecidos ósseo, muscular e adiposo assemelharam -se aos verificados nos cordeiros Santa Inês. Nesse caso, a diferença de raças não influenciou as forma de crescimento destes tecidos na carcaça. WYNN e THWAITES (1981) encontraram, para cordeiros cruzados, coeficientes alométricos de crescimento de

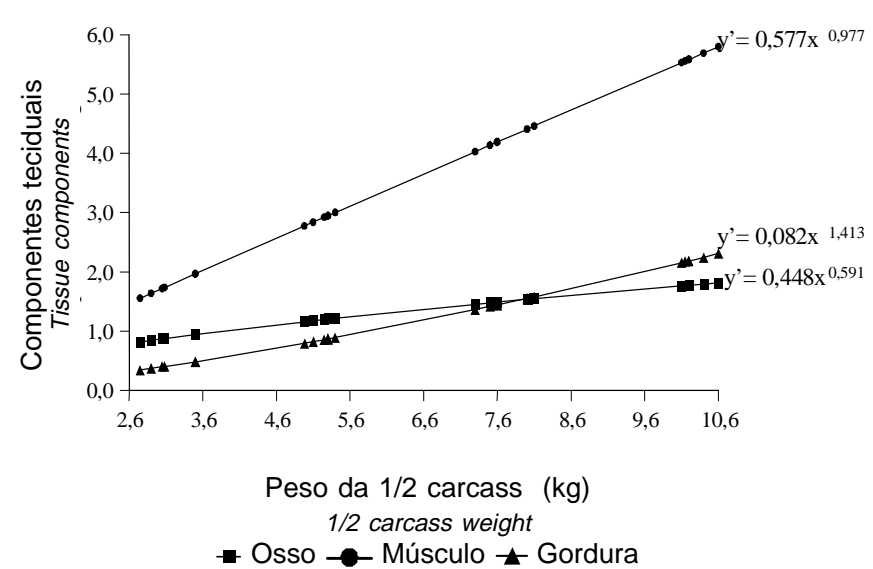

Figura 2 - Crescimento alométrico dos componentes teciduais, osso, músculo e gordura, em relação à meia carcaça de cordeiros Santa Inês.

Figure 2 - Allometric growth of the tissue components, bone, muscle and fat in relation to $1 / 2$ carcass of Santa Ines lambs. osso, músculo e gordura, de 0,586, 0,875 e 1,99, respectivamente, em relação ao peso da meia carcaça, confirmando também o crescimento precoce para o osso, o intermediário para o músculo e tardio para a gordura.

Huidobro e Villapadierna (1992), citados por SILVA (1999), verificaram coeficientes de crescimento menor que $1(<1)$ para osso $(b=0,9056)$ e igual a 1 para o músculo $(\mathrm{b}=0,9557)$ e gordura total $(b=1,2345)$ em relação ao peso da $1 / 2$ carcaça. OSÓRIO e GUERREIRO (1994), trabalhando com animais cruzados, encontraram coeficientes alométricos de osso, músculo e gordura em relação ao peso vivo 0,$684 ; 1,115$; e 2,168 , respectivamente.

$\mathrm{Na}$ Figura 3, são apresentadas as equações de alometria e as respectivas linhas de regressão para os componentes teciduais na carcaça de cordeiros Bergamácia. Observou-se que o tecido muscular apresentou desenvolvimento relativo semelhante ao da meia carcaça, enquanto o tecido ósseo se desenvolveu precocemente e o adiposo aumentou seu ritmo de crescimento, quando a meia carcaça conferiu peso mais elevado.

$\mathrm{Na}$ Figura 4 observa-se o comportamento alométrico dos componentes teciduais (osso, músculo e gordura), por meio da linha traçada no intervalo de peso considerado. Observou-se menor desenvolvi- 
Rev. bras. zootec.

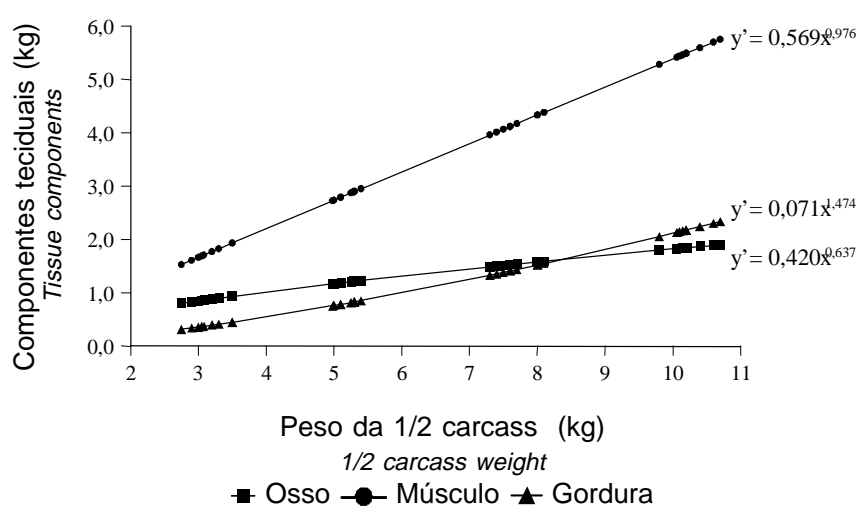

Figura 3 - Crescimento alométrico dos componentes teciduais, osso, músculo e gordura, em relação a $1 / 2$ carcaça de cordeiros Bergamácia.

Figure 3 - Allometric growth of the tissue components, bone, muscle and fat, in relation to $1 / 2$ carcass of Bergamacia lambs.

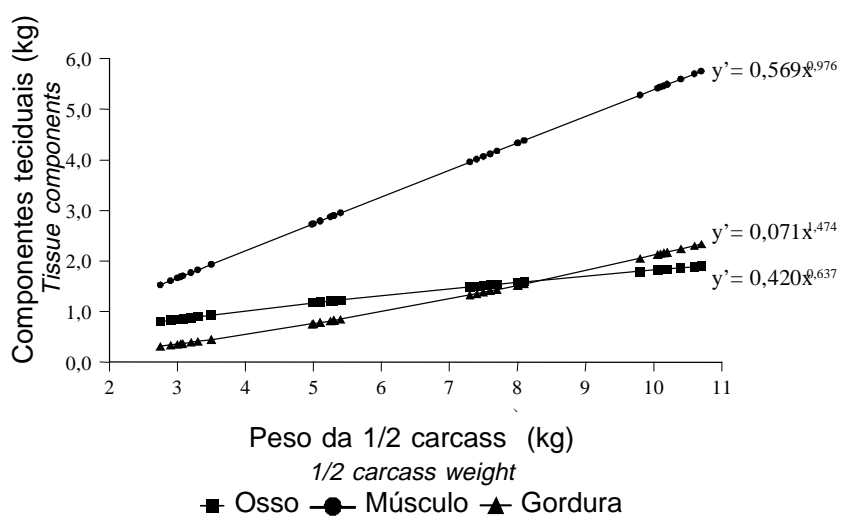

Figura 4 - Crescimento alométrico dos componentes teciduais em relação a $1 / 2$ carcaça dos animais experimentais.

Figure 4 - Allometric growth of the tissue components in relation to $1 / 2$ carcass of the experimental animals.

mento relativo do tecido ósseo entre os pesos de 8 a $9 \mathrm{~kg}$ de meia carcaça e aumento da deposição de gordura. Pode-se inferir, portanto, que até o peso de $9 \mathrm{~kg}$ a carcaça tem qualidade elevada, em se tratando de deposição de gordura.

Verificando-se os coeficientes de alometria dos tecidos ósseo, muscular e adiposo, na Tabela 4, em relação ao peso da $1 / 2$ carcaça, constatou-se que o tipo de crescimento destes tecidos são os mesmos para os cordeiros Santa Inês e Bergamácia.
Tabela 4 - Estimativas dos coeficientes de alometria (b) dos componentes teciduais (osso, músculo e gordura) da meia carcaça dos animais experimentais e a verificação de sua diferença com a unidade e seu respectivo erro-padrão $(\mathrm{Sd})$

Table 4 - Estimates of the allometry coefficient (b) of the tissue components (bone, muscle and fat) of the $1 / 2$ carcass of the experimental animals and corroboration of its difference with the unit and its respective standard error (Sd)

\begin{tabular}{|c|c|c|c|}
\hline $\begin{array}{l}\text { Raça } \\
\text { Breed }\end{array}$ & $\begin{array}{l}\text { Osso } \\
\text { Bone } \\
\mathrm{b}(\mathrm{Sd})\end{array}$ & $\begin{array}{c}\text { Músculo } \\
\text { Muscle } \\
\text { b(Sd) }\end{array}$ & $\begin{array}{c}\text { Gordura } \\
\text { Fat } \\
\text { b }(\mathrm{Sd})\end{array}$ \\
\hline $\begin{array}{l}\text { Santa Inês } \\
\text { Santa Ines }\end{array}$ & $0,591 * *(0,037)$ & $0,977^{\mathrm{ns}}(0,035)$ & $1,413 * *(0,075)$ \\
\hline $\begin{array}{l}\text { Bergamácia } \\
\text { Bergamacia }\end{array}$ & $0,737 * *(0,083)$ & $0,974 *(0,040)$ & $1,680 * *(0,154)$ \\
\hline Geral & $0,637^{* *}(0,038)$ & $0,976^{\mathrm{ns}}(0,027)$ & $1,474 * *(0,073)$ \\
\hline
\end{tabular}

* Siginificativo a $5 \%$ de probabilidade.

** Significativo a $1 \%$ de probabilidade.

* Significant at $5 \%$ of probability.

** Significant at $1 \%$ of probability.

\section{Conclusões}

O tecido ósseo apresentou crescimento heterogônico negativo; o muscular, isogônico; e o adiposo, heterogônico positivo, em relação ao peso da $1 / 2$ carcaça dos cordeiros Santa Inês e Bergamácia, o que leva a inferir que o peso de abate de cordeiros destas raças esteja na faixa de 25 a $35 \mathrm{~kg}$ de peso vivo, uma vez que a deposição acentudada de tecido adiposo se iniciou a partir dos $35 \mathrm{~kg}$ de peso vivo.

\section{Referências Bibliográficas}

AGRICULTURAL RESEARCH COUNCIL - ARC. 1980 The nutrient requeriments os farm livestock. London. 351p. BERG, R.I., BUTTERFIELD, R M.1976. New concepts of cattle growth. Sidney: Sudney University Press. 240p.

BERG, R.T., ANDERSEN, B.B., LIBORIUSSEN, T. 1978. Growth of bovine tissues. 1. Genetic influence on growth patterns muscle, fat and bone in young bull. Anim. Prod., 26(3):245-258.

FERREIRA, M.A. Desempenho, exigências nutricionais e eficiência de utilização de energia metabolizável para ganho de peso de bovinos F1. Simental x Nelore. Viçosa, MG: UFV. 1997. 97p. Dissertação (Mestrado em Zootecnia) - Universidade Federal de Viçosa, 1997.

FORREST, J.C., ABERLE, E.D., HEDRICK, H.B.et al. 1979. Fundamentos de la ciencia de la carne. Zaragoza: Acribia. 364p.

GERASSEV, L.C. Composição corporal e exigências em macrominerais ( $\mathrm{Ca}, \mathrm{P}, \mathrm{Mg}, \mathrm{Ke} \mathrm{Na}$ ) de cordeiros Santa Inês. Lavras, MG, 1998. 99p. Dissertação (Mestrado em Zootecnia) Universidade Federal de Lavras, 1998. 
GALVÃO, J.G.C. , FONTES, C.A.A ., PIRES, C.C. et al. 1991. Características e composição física da carcaça de bovinos não castrados, abatidos em 3 estágios de maturidade de três grupos raciais. R. Soc. Bras. Zootec., 20(5):502-512.

HUXLEY, J.S. 1932. Problems of relative growth. London: Methuen. 577p.

MARPLE. D.N. Principles of growth and development. In: GROWTH MANAGEMENT CONFERENCE, 1983, Indiana. Proceedings ... Indiana: IMC, 1983. p.1-6.

MÜLLER, L., PRIMO, A.T. 1986. Influência do regime alimentar no crescimento e terminação de bovinos e na qualidade da carcaça. Pesq. Agrop. Bras., 21(4):445- 452.

OSÓRIO, J.C.S., GUERREIRO, J.L.V. 1994. Produção de carne na raça Ideal. Pelotas. 234p.

OWENS, F.N., DUBESKI, P., HANSON, C.F. 1993. Factors that alter the growth and desvelopment of ruminants. J. Anim. Sci., 71(11):3138-3150.

SAINZ, R.D. Qualidade de carcaças e de carne de ovinos e caprinos. In: REUNIÃO ANUAL DA SOCIEDADE BRASILEIRA DE ZOOTECNIA, 33, 1996, Fortaleza, CE. Anais... Fortaleza: SBZ, 1996. p.3-14.
SAS INSTITUTE. 1996. In: Procedures. Versão 6, v.1. 3.ed. Cray.

SILVA, L.F. Crescimento, composição corporal e exigências nutricionais de cordeiros abatidos com diferentes pesos. Santa Maria, RS, 1999. 65p. Dissertação (Mestrado em Produção Animal ) - Faculdade de Ciências Agrárias e Veterinárias, Universidade Estadual Paulista, 1999.

WYNN, P.C., THAITES, C.J. 1981. The relative growth and development of the carcass tissues of merino and crossbred rams and wethers. Austr. J. Agric. Rev., 32:947-956.

Recebido em: 24/05/00

Aceito em: 06/10/00 